Article

\title{
Assessment of a Rock Pillar Failure by Using Change Detection Analysis and FEM Modelling
}

\author{
Claudio Vanneschi ${ }^{1}$, Giovanni Mastrorocco ${ }^{2}$ (D) and Riccardo Salvini $^{1, *}$ (D) \\ 1 Department of Environment, Earth and Physical Sciences and Centre of GeoTechnologies CGT, \\ University of Siena, Via Vetri Vecchi 34, 52027 San Giovanni Valdarno, Italy; claudio.vanneschi@unisi.it \\ 2 Sole Proprietorship, Via Marco Polo 9, 84043 Agropoli, Italy; info.giovanni.mastrorocco@gmail.com \\ * Correspondence: riccardo.salvini@unisi.it
}

Citation: Vanneschi, C:

Mastrorocco, G.; Salvini, R

Assessment of a Rock Pillar Failure by Using Change Detection Analysis and FEM Modelling. ISPRS Int. J. Geo-Inf. 2021, 10, 774. https://doi.org/ 10.3390/ijgi10110774

Academic Editor: Wolfgang Kainz

Received: 27 July 2021

Accepted: 6 November 2021

Published: 13 November 2021

Publisher's Note: MDPI stays neutral with regard to jurisdictional claims in published maps and institutional affiliations.

Copyright: (c) 2021 by the authors. Licensee MDPI, Basel, Switzerland. This article is an open access article distributed under the terms and conditions of the Creative Commons Attribution (CC BY) license (https:// creativecommons.org/licenses/by/ $4.0 /)$.
Abstract: In this paper, various methods have been used to control and evaluate engineering difficulties in mining accurately. Different unstable scenarios occurring at the surfaces of underground mine walls, have been identified by comparing 3D terrestrial laser scanning surveys and subsequent point cloud 3D analysis. These techniques, combined with a change detection analysis approach and the integration of rock mechanics' modelling, represent an asset for the assessment and management of the risk in mining. The change detection analysis can be used as control of mining and industrial processes as well as to identify valid model scenarios for establishing possible failure causes. A pillar spalling failure has been identified in an Italian underground marble quarry and this topic represents the basis of the present paper. A Finite-Element Method was used to verify the occurrence of relatively high-stress concentrations in the pillar. The FEM modelling revealed that stresses in the proximity of the pillar may have sufficient magnitude to induce cracks growth and spalling failure.

Keywords: multitemporal terrestrial laser scanning; rock pillar failure; underground quarry; finite element method

\section{Introduction}

In the last decades, there has been significant progress towards methods aimed at identifying the aspects that control the rock mass behaviour for preserving personnel safety and commercial productivity in rock mining. Thanks to technological advances, it is possible to obtain detailed information concerning morphometric measurements (e.g., changes in excavation morphologies, dimensions, and surveying of as-built layouts). Similarly, detailed 3D models of both surface and underground excavations can be easily produced. Laser Scanning (LS) and Digital Photogrammetry (DP) techniques and topographic surveying through modern Total Station (TS) and Global Navigation Satellite System (GNSS), allow for the acquisition and georeferencing of highly detailed spatial info (i.e., 3D clouds constituted by millions of points). LS and DP can be used to perform structural geological analyses and slope stability assessments of rock masses [1-8], to identify rock failure precursors [9], for geological data collection [10-13] and to analyse an active bedrock normal fault scarp based on kinematic indicators reconstruction [14].

Notwithstanding the advantages of remote sensing techniques, conventional in-situ surveys, such as geological and engineering-geological mapping, still provide a source of fundamental data that both validates and integrates the information possibly acquired using LS and DP. When used together, remote sensing and conventional mapping techniques allow reducing data uncertainty and provide spatial completeness, accuracy, and a better characterisation of data variability. Indeed, the reliability of rock engineering analysis depends on the quality, quantity, and interpretation of available information. Data collection and data management, indeed, are mandatory requirements in rock mechanics, and they represent the only way to decrease uncertainty. 
A further application of LS and DP is represented by multitemporal analysis, since the acquisition of a large amount of data, in a very short time allows to perform accurate 3D comparison even in complex morphologies [15-18]. Multitemporal Terrestrial Laser Scanning (M-TLS), used in this study, is, therefore, a useful and capable method for the analysis of mine environments through time, helping in identifying critical areas for further rock mechanic investigations. M-TLS and subsequent 3D analysis through change detection techniques can be used for the assessment and management of the mining risk, and they are usually integrated into mine planning and design processes. This is particularly important when complex geotechnical problems are involved, highlighting areas that might be worth considering for in-depth geo-mechanical analysis.

In this context, many design structures in mining practice require detailed rock mechanics analyses using accurate data and advanced numerical tools. Stress and stability analyses, indeed, can be carried out using continuous and/or discontinuous numerical approaches, and they are currently used in the civil and mining engineering sectors due to the possibility to take account of complex rock mass deformation and failure [19-21].

The integration of these methods was applied in this paper to an Italian underground marble mine complex composed of three different quarries named, respectively, Tacca Bianca, Fitta and Macchietta; the latter is the only active quarry and represents the case study of this paper. Field surveys started in May 2014 using geomatics, geological and engineering-geological techniques. Due to stability issues of the quarry walls, a further geomatic survey was carried out in February 2016 with the goal of measuring walls morphological variations and performing a stability analysis of the quarry. Moreover, to obtain the full extent of the whole underground marble mine complex and to use the exact morphologies and geospatial positions into numerical models, the Fitta and Tacca Bianca quarries were also considered during the second and a third LS surveys, respectively.

The use of M-TLS has allowed the realization of a change detection analysis capable of identifying modified areas within the active quarry by using the Multiscale Model-toModel Cloud Comparison (M3C2) algorithm [16]. This algorithm has the advantage of employing point cloud data to perform accurate change detection inspection, reducing the approximations derived from using surface meshing techniques or Digital Surface Models (DSMs).

Unfortunately, a pillar spalling failure was identified inside the underground part of the Macchietta quarry (Figure 1). Despite the focus of the paper being change detection analysis, due to this event, this area was analysed using a preliminary elastic Finite Element Method (FEM) approach to verify the possibility of critical stress concentrations that may lead to the accumulation and growth of stress-induced fractures (i.e., spalling behaviour). 


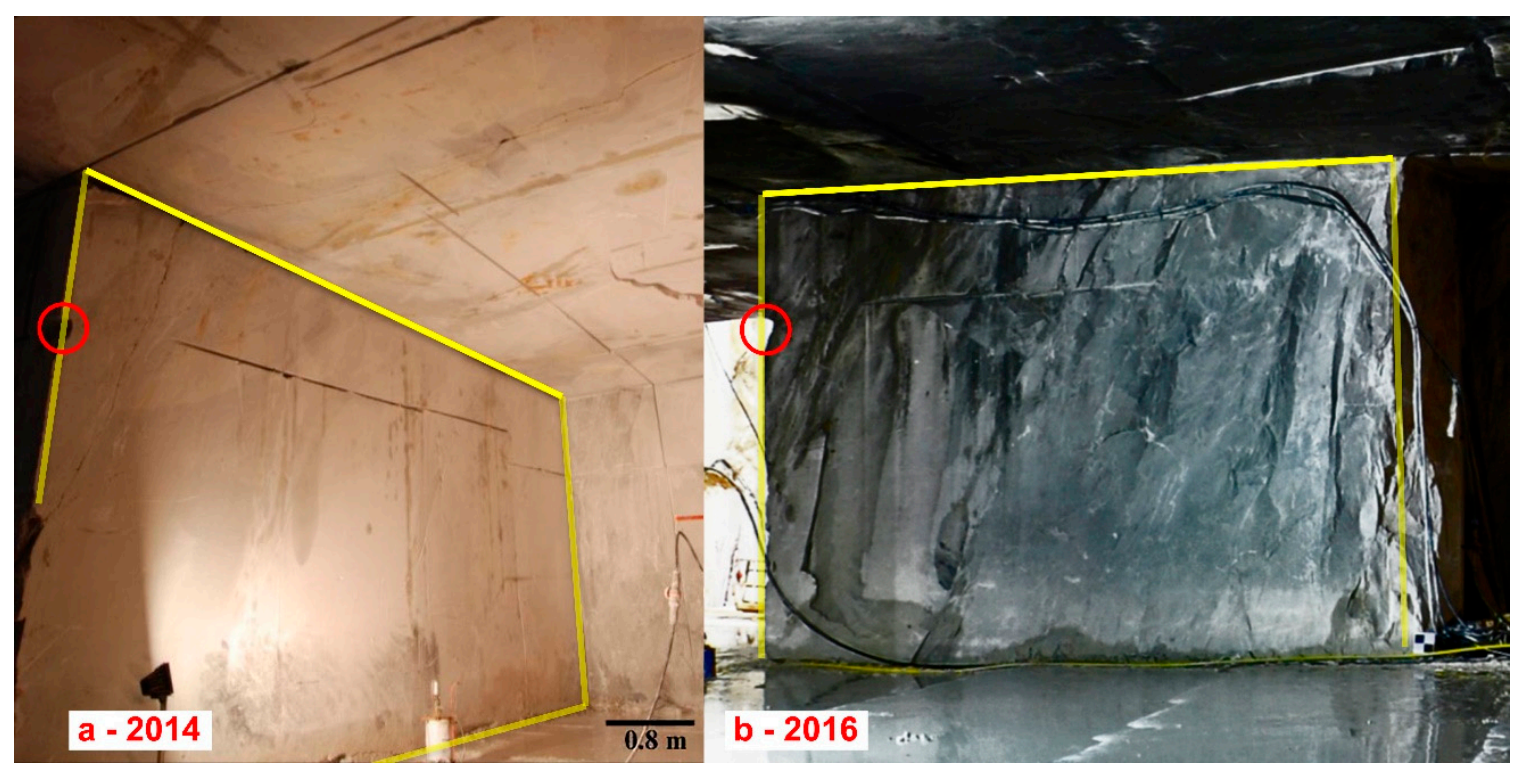

Figure 1. Pillar structural condition in 2014 (a)—regular rocky surface after excavation) and 2016 (b) —rough rocky surface after spalling). The yellow box represents the same cutting surface. A common point between the images is highlighted by a red circle. Due to the prospective view, the scale bar is indicative only.

\section{Geographical and Geological Setting}

The study focuses on a marble quarry complex located in the Apuan Alps marble district in the province of Lucca (Italy). The whole area takes its name from the Tacca Bianca quarry, located almost $100 \mathrm{~m}$ above. The quarry understudy, named Macchietta, represents the lower and latest portion of the complex and merges itself with the intermediate and abandoned Fitta quarry. The entrance of the Macchietta quarry is located at $1080 \mathrm{~m}$ above sea level ( $m$ a.s.l.), with the exploitation area composed of three different tunnels with bottom and roof at 1108 and $1114 \mathrm{~m}$ a.s.l, respectively.

The quarry is in the S-W side of Mt. Altissimo syncline, belonging to the Apuan Unit (Figure 2). The marble-cored of the Mt. Altissimo syncline is the result of the compressional tectonics of the Tertiary orogenesis, which can be related to the D1 phase of Carmignani and Kligfield [22]. The compressive tectonics generated kilometric-scale to microscopic isoclinal-subisoclinal synmetamorphic folds (NE-verging), associated with a penetrative axial planar S1 foliation and L1 stretching lineation. The D1 structural setting reveals a composite origin resulting from the local superposition of two generations of structures related to successive deformation stages [23]. The Mt. Altissimo syncline and its inverted limb are severely affected by the subsequent D2 tectonic phase of extensional characteristics. This phase generated non-cylindrical parasitic folds, with sub-horizontal axial planar crenulations, characterised by hectometric to microscopic scale (SW-verging); the partitioning of deformation was strong and controlled by the difference in rock-types inherited from the D1 strain features.

The mining area involves the youngest lithologies in the core of the Mt. Altissimo syncline ([23,24] and reference therein) consisting of White Marble, Ordinary Marble and Veneid Marble (Hettangian). It is characterised by the presence of foliation structures belonging to both D1 and D2 tectonic events and a widespread network of joints and faults with sub-metric to few metres long offsets (Figure 3). 

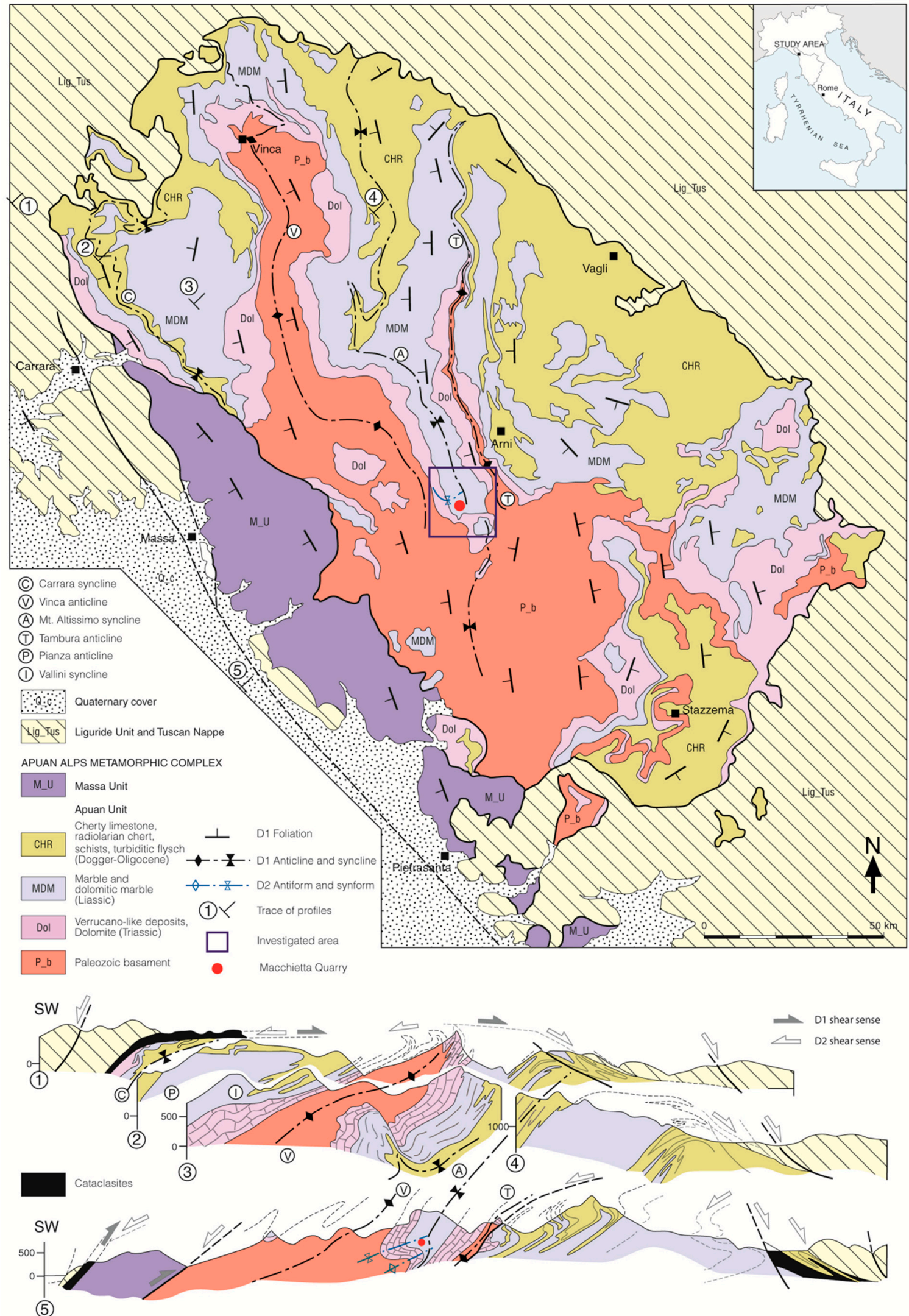

Figure 2. Simplified geological map of the Apuan Alps; the investigated area is highlighted with a rectangle and the location of the quarry is indicated by a point (modified after [25]). 

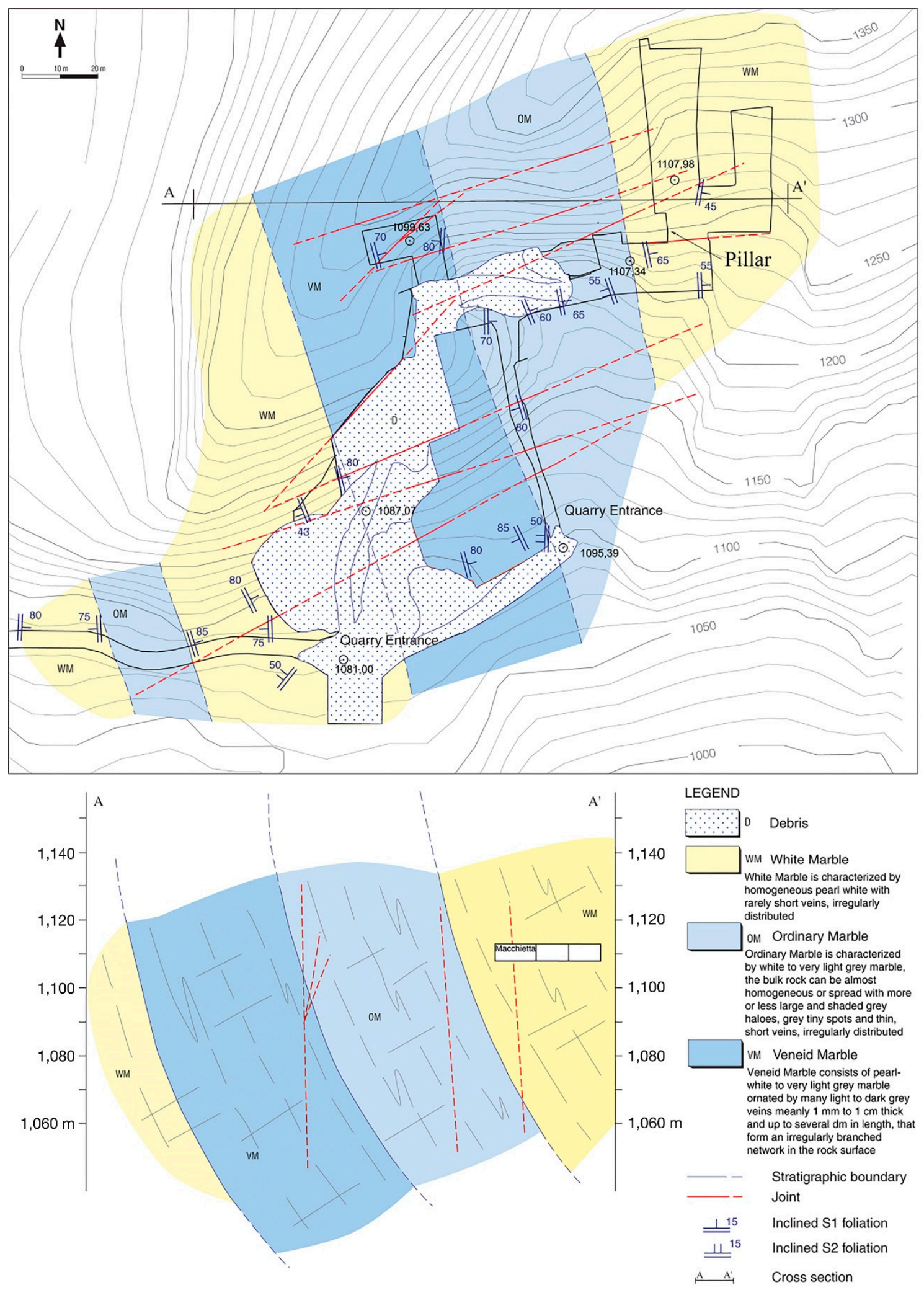

Figure 3. Geological map and geological cross-section (AA') of the Macchietta quarry with the distribution of joint and marble types. 


\section{Methods}

\subsection{Geomatic Surveys}

The morphology of the Macchietta quarry and its multitemporal evolution was investigated through 2 georeferenced TLS surveys. The first survey was executed in May 2014 by using a ScanStation2 device (Leica Geosystems AG, San Gallo, Switzerland), Table 1. The scanner was alternated with a Nikon ${ }^{\mathrm{TM}}$ D80 digital camera to acquire high-resolution images later aligned to the point cloud using methods already described in [6]. Considering the complex shape of the quarry and the need to minimise shadows in the data, 9 laser stations were executed ( 2 of which were outside of the underground quarry) with a scanning spatial resolution set to $0.05 \mathrm{~m}$ at a distance of $50 \mathrm{~m}$.

Table 1. Utilised terrestrial laser scanners and cameras specifications.

\begin{tabular}{|c|c|c|c|c|c|}
\hline $\begin{array}{l}\text { TLS Type } \\
\text { (Year 2014) }\end{array}$ & Range (m) & $\begin{array}{l}\text { Scan Rate } \\
\text { (pts/sec) }\end{array}$ & $\begin{array}{l}\text { Accuracy of a Single } \\
\text { Measurement (m) at } \\
1 \mathrm{~m}-50 \mathrm{~m} \text {, One Sigma }\end{array}$ & $\begin{array}{l}\text { Angular Accuracy } \\
\text { (Horizontal/ } \\
\text { Vertical- } \mu \text { rad), } \\
\text { One Sigma }\end{array}$ & \\
\hline $\begin{array}{c}\text { Leica } \\
\text { ScanStation } 2\end{array}$ & $\begin{array}{c}300 \mathrm{~m} @ 90 \% ; 134 \\
\mathrm{~m} @ 18 \% \\
\text { reflectivity }\end{array}$ & Up to 50,000 & $\begin{array}{l}0.004 \text { (distance) } \\
0.006 \text { (position) }\end{array}$ & 60 & \\
\hline $\begin{array}{c}\text { Camera } \\
\text { (year 2014) }\end{array}$ & Sensor type & Sensor size $(\mathrm{mm})$ & Image size (pixel) & Pixel size (mm) & $\begin{array}{l}\text { Focal length } \\
(\mathrm{mm})\end{array}$ \\
\hline Nikon D80 & CCD & $23.60 \times 15.80$ & $3872 \times 2592$ & 0.00609 & 18.0 \\
\hline TLS (year 2016) & Range (m) & $\begin{array}{l}\text { Scan Rate } \\
\text { (pts/sec) }\end{array}$ & $\begin{array}{l}\text { Accuracy of a Single } \\
\text { Measurement (m) at } \\
2 \mathrm{~m}-80 \mathrm{~m} \text {, One Sigma }\end{array}$ & $\begin{array}{c}\text { Angular Accuracy } \\
\text { (Horizontal/ } \\
\text { Vertical- } \mu \text { rad), } \\
\text { One Sigma }\end{array}$ & \\
\hline Trimble TX8 & $\begin{array}{c}340 \mathrm{~m} @ 90 \% \\
\text { reflectivity }\end{array}$ & $1,000,000$ & $<0.002$ (distance) & 80 & \\
\hline $\begin{array}{c}\text { Camera } \\
\text { (year 2016) }\end{array}$ & Sensor type & Sensor size $(\mathrm{mm})$ & Image size (pixel) & Pixel size $(\mathrm{mm})$ & $\begin{array}{l}\text { Focal length } \\
(\mathrm{mm})\end{array}$ \\
\hline Nikon D7100 & CMOS & $23.50 \times 15.60$ & $6000 \times 4000$ & 0.25531 & 18.0 \\
\hline
\end{tabular}

During the TLS survey, a conventional topographic field survey, using 2 GNSS geodetic receivers and a reflectorless TS, was carried out in order to register and to georeference, with adequate spatial accuracy, the resultant point clouds. A total of 57 targets, acting as physical constraints in the roto-translation of point clouds, were placed uniformly over the scan scenes (at least 5 targets for each scan with the goal of limiting errors and improving accuracy) and measured using the TS with millimetric accuracy. Five HighDefinition Surveying (HDS) targets were screwed on metal plates solidly and permanently fixed on the rock walls in unserved external quarry areas in a way it was possible to re-measure them during the further TLS surveys. Two GNSS receivers, operating in static modality and recording continuous signals from the satellite constellation for more than $3 \mathrm{~h}$, were located in the external service area of the underground quarry and used to obtain the geographic coordinates of the origin of the TS survey and its 0-azimuth direction. Therefore, the TS survey had origin in the vicinity of the GNSS device (external service area) and continued inside the underground quarry by using traditional topographic techniques (i.e., Intersection Method).

By means of a topographic intersection using the TS, a millimetric error was achieved when measuring the 5 HDS targets of the permanent network in February 2016. In this way, similarly as for the 2014 survey, a series of 37 targets were uniformly distributed within the quarry areas and measured by using a TS with the goal of georeferencing the new point cloud and to register it to the previous one (year 2014-point cloud).

During the second TLS survey, a Trimble ${ }^{\mathrm{TM}} \mathrm{TX} 8$ device was used (Table 1), and the Fitta quarry was included in the scanned areas. The scanner, in this case, was alternated with a Nikon ${ }^{\mathrm{TM}}$ D7100 digital camera with the goal of acquiring co-axial photos to be used for point cloud texturing. Point clouds were measured from eight different scanning 
positions underground, with the scanning resolution set to $0.01 \mathrm{~m}$ at a distance of $50 \mathrm{~m}$ (standard mode).

The Tacca Bianca quarry was surveyed following the same devices and approaches used during the second survey. A total of 14 scans were realised, 4 of which were outside of the underground mine. The scanning resolution was set to $0.01 \mathrm{~m}$ at a distance of $50 \mathrm{~m}$ (standard mode).

\subsection{Change Detection Analysis}

The M3C2 plug-in of CloudCompare open-source software was used to perform an accurate change detection analysis directly using the point clouds acquired in 2 different periods [16]. The plug-in computes the local distance $\left(\mathrm{L}_{\mathrm{M} 3 \mathrm{C} 2(\mathrm{i})}\right)$ between 2 point clouds along the normal surface direction only if it intersects any points on the final point cloud. Additionally, the algorithm estimates a confidence interval at $95 \%\left(\mathrm{LOD}_{95 \%(\mathrm{~d})}\right)$ based on Gaussian statistics (Equation (1)) for each distance in such a way to know if a significant change was detected or not. The distance accuracy and the reliability of the resulting change depend on point the cloud roughness $\left(\sigma_{\mathrm{i}}\right)$ and registration error (reg).

$$
\operatorname{LOD}_{95 \%(d)}= \pm 1.96\left(\sqrt{\frac{\sigma_{1}(d)^{2}}{n_{1}}+\frac{\sigma_{2}\left(d^{2}\right)}{n_{2}}}+r e g\right)
$$

Equation (1) is function of "reg" and local cloud roughness $\sigma_{1}$ and $\sigma_{2}$ computed on the two sub-clouds $\mathrm{n}_{1}$ and $\mathrm{n}_{2}$ at the projection scale " $\mathrm{d}$ " used to measure the distance between the reference and compared point clouds. The test was statistically significant if the detection value $\left(\mathrm{LOD}_{95 \%(\mathrm{~d})}\right)$ was shorter than the measured distance $\left(\mathrm{L}_{\mathrm{M} 3 \mathrm{C} 2(\mathrm{~d})}\right)$, with $\mathrm{n}_{1}$ and $\mathrm{n}_{2}$ greater than 4 . Conversely, the $\mathrm{LOD}_{95 \%(\mathrm{~d})}$ value was considered non-significant if the level of detection overcame the measured distance.

The change detection analysis for the Macchietta quarry data followed 2 steps: (1) analysis of the areas changed in time to identify valid model scenarios; (2) high precision measurement of morphological variations of the identified failure.

\subsubsection{Step 1: Identification of Valid Model Scenarios}

The change detection analysis was carried out comparing several portions of the point clouds. Due to both morphological complexity of the quarry walls and normal computation influence on the $\mathrm{L}_{\mathrm{M} 3 \mathrm{C} 2(\mathrm{i})}$ value, the quarry was segmented into 68 homogenous areas (subparallel point cloud pairs).

The point cloud generated in 2014 was generally used as a reference due to its higher volume density $\left(1270.49 \mathrm{pts} / \mathrm{m}^{3}\right)$, whereas the point cloud acquired in 2016 was used as the compared cloud $\left(1243.68 \mathrm{pts} / \mathrm{m}^{3}\right)$. Only in specific cases the split point cloud from 2016 was used as a reference because of a local higher density. Furthermore, the point clouds were sub-sampled at $0.05 \mathrm{~m}$ and cleaned up, removing machines, workers and tools (a further detailed editing was necessary during the second step analysis). Each pair of point clouds was run separately to use different values of normal scale, projection scale and maximum length of the cylinder (Table 2). The normal scale (D in Table 2) corresponds to the diameter of a disk centred in a given core point " $\mathrm{i}$ ". The disk comprises neighbour points, utilised to automatically fit a plane from which a normal vector is defined [16]. A uniform normal scale, or a range of normal scales, can be iteratively applied to the considered point cloud. The orientation of the normal (i.e., vertical or horizontal) can be also selected. " $\mathrm{d}$ " in Table 2 is the diameter of a cylinder, which intersects the clouds under comparison and, going through a given point " $\mathrm{i}$ ", it has the major axis oriented along the normal vector. The cylinder separates 2 subsets from the clouds, whose mean distribution gives their average positions, $i_{1}$ and $i_{2}$. By this method, the local distance between the point clouds corresponds to the length of the major axis segment between $i_{1}$ and $i_{2}$. The length standard deviation estimates the point cloud roughness along the normal direction. 
The max cylinder depth corresponds to the magnitude of difference between the compared point clouds. In some cases (e.g., missing blocks due to excavation activities), it was necessary to adjust the cylinder maximum length to increase the computational intensity of difference between the 2 clouds. For each pair of point clouds, a properly orientation of the normal was used and a total "reg" value of about $0.005 \mathrm{~m}$ was calculated; this value was obtained by considering the propagation of the mean absolute errors computed for both the 2014 ( mae $\left._{2014}\right)$ and 2016 TLS data (mae 2016$)$ as it follows ([26]-Equation (2)):

$$
\operatorname{reg}=\sqrt{\left(\text { mea }_{2014}\right)^{2}+\left(\text { mea }_{2016}\right)^{2}}
$$

Table 2. Parameters used for detecting morphological point cloud changes for Step 1 and Step 2.

\begin{tabular}{ccccc}
\hline Step 1 & $\mathbf{D}(\mathbf{m})$ & $\mathbf{d}(\mathbf{m})$ & $\mathbf{1}(\mathbf{m})$ & Axis \\
\hline & $0.2<\mathrm{D}<0.75$ & $0.1<\mathrm{d}<0.328$ & $\begin{array}{c}0.252<1< \\
2.150\end{array}$ & Variable \\
\hline Step 2 & $\mathbf{D}(\mathbf{m})$ & $\mathbf{d ~ ( m )}$ & $\mathbf{1 ~ ( m ) ~}$ & Axis \\
\hline N-S (Eastern wall) & 0.496 & 0.124 & 0.519 & $-\mathrm{x}$ \\
\hline E-W (Southern wall) & 0.383 & 0.095 & 0.672 & $\mathrm{y}$ \\
\hline N-S (Western wall) & 0.359 & 0.089 & 0.318 & $\mathrm{x}$
\end{tabular}

Note: $\mathrm{D}=$ normal scale, $\mathrm{d}$ = projection scale, $\mathrm{l}=$ maximum length of the cylinder, Axis = normal user-defined orientation. The Axis directions were oriented in such a way that the software returned negative distances in case of rock erosion and positive distances in case of movement away from the rock face. The quarry floor was not included in the analyses.

\subsubsection{Step 2: Change Detection Analysis of the Identified Failure}

Point clouds referring to the quarry sidewalls in the identified damage area were not sub-sampled, additional editing was still necessary to remove small electrical cables and worker tools that did not influence the first step outcome, allowing to carry out a high precision analysis and to avoid false distances in the output results. Distances of every face of the analysed pillar were computed separately by using the parameters shown of Table 2 . A registration error (reg) of $0.005 \mathrm{~m}$, as computed in Step 1, was used.

\subsection{Sidewalls Analysis by Numerical Modelling}

With the aim of understanding and relating the $\mathrm{M} 3 \mathrm{C} 2$ distance results to the possible mechanical behaviour of the rock mass, numerical analyses were carried out using the FEM code RS3 (Rocscience ${ }^{\mathrm{TM}}$ ). The model, shown in Figure 4, was generated using a simplified geometry elaborated from the 3D point cloud obtained from 2016 TLS, while the external surface boundary, which defines the extents of the FEM mesh, was added by using a topographic section obtained from the Tuscany Region Digital Terrain Model $(10 \times 10 \mathrm{~m}$ cell resolution).

The number of edges of the external and excavation boundaries were kept to a minimum, but at the same time sufficient to obtain a simple good quality mesh (this strategy is useful to limit useless computing time). Then, the mesh was customised by increasing the element density in the proximity of areas under consideration. Simplified geometries for the Tacca Bianca and the Fitta quarries were also used in the model due to the limited information available about the excavation time-sequencing for those extraction sites. An excavation-relaxation approach was used to simulate the progressive advance of the Macchietta quarry (1 $\mathrm{m}$ user-defined progressive excavation advance). This approach allowed for a gradual reduction of the forces applied to the excavation boundaries. 


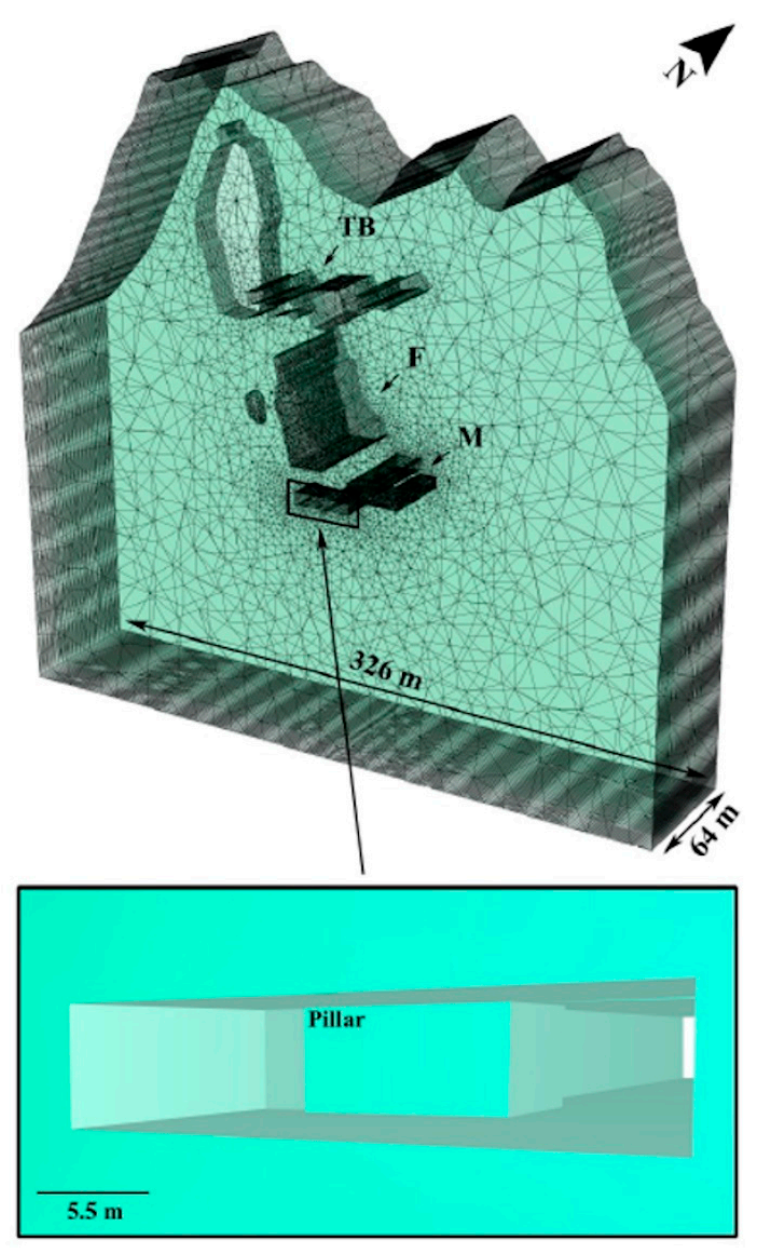

Figure 4. FEM geometry. From the bottom to the top, it is possible to recognize the Macchietta quarry (M), the Fitta quarry (F) and the Tacca Bianca quarry (TB). Being a perspective view, the scale bars are indicative only.

The material properties were defined using the RocData code (Rocscience ${ }^{\mathrm{TM}}$ ), taking into consideration the intact rock material properties shown in Table 3. The results of new laboratory tests were used to constrain the material properties used in the numerical model (Table 4). Note that the strength of the marble material was scaled using the relation proposed by [27] to account for the mesh size used in the model. Elmo et al. [28] found that this approach was suitable for the calibration of intact and rock mass properties in FEM analyses. Two mesh sizes were considered in the model, $0.8 \mathrm{~m}$ (in the near surroundings the Macchietta quarry) and $2 \mathrm{~m}$ (for the whole simulation). Following these characteristics, the calculated uniaxial compressive strengths were $73 \mathrm{MPa}$ and $62 \mathrm{MPa}$, respectively (Table 3). The effects of foliation on the modelling results were tested by using an isotropic elastic material (i.e., no foliation) and an elastic transversely anisotropic material (i.e., foliation coincident with the anisotropic plane).

Table 3. Intact rock properties from literature.

\begin{tabular}{cccccccccc}
\hline Model Type & E (GPa) & $v$ & $\rho(\mathrm{Kg} / \mathrm{m} 3)$ & $\sigma \mathrm{c50}(\mathrm{MPa})$ & $\boldsymbol{\sigma c}(\mathrm{MPa})$ & $\mathrm{c}(\mathrm{MPa})$ & $\boldsymbol{\phi}(\mathrm{Degrees})$ & $\sigma \mathrm{t}(\mathrm{MPa})$ \\
\hline Mesh $0.8 \mathrm{~m}$ & 57.950 & 0.27 & 2701 & 120 & 73 & 4.382 & 41.450 & 1.232 \\
\hline Mesh $2.0 \mathrm{~m}$ & 57.950 & 0.27 & 2701 & 120 & 62 & 3.984 & 40.196 & 1.046 \\
\hline
\end{tabular}

$\mathrm{E}=$ Young's modulus $(\mathrm{GPa}) ; v=$ Poisson's ratio; $\rho=$ density $\left(\mathrm{Kg} / \mathrm{m}^{3}\right) ; \sigma c 50=$ Uniaxial Compressive Strength of a 50 mm diameter sample $(\mathrm{MPa}) ; \sigma \mathrm{c}=$ Uniaxial Compressive Strength at the scale defined by the mesh size $(\mathrm{MPa}) ; \mathrm{c}=$ cohesion $(\mathrm{MPa}) ; \phi=$ friction angle; $\sigma_{\mathrm{t}}=$ tensile strength (MPa). 
Table 4. Intact rock properties from new laboratory tests.

\begin{tabular}{cccccc}
\hline Test Type & Id Sample & E (GPa) & $\boldsymbol{v}$ & $\boldsymbol{\sigma c 5 0 ~ ( M P a )}$ & $\boldsymbol{\sigma t 5 0 ~ ( M P a )}$ \\
\hline Brazilian & C13C & - & - & - & 6.165 \\
\hline Brazilian & C13D & - & - & - & 4.520 \\
\hline Point Load Test & Average & - & - & 98 & 5.128 \\
\hline UCS & C1 & 51 & 0.25 & 121 & - \\
\hline UCS & C7 & 76 & - & 123 & - \\
\hline UCS & C8 & 54 & 0.36 & 98 & - \\
\hline UCS & C9 & 58 & 0.36 & 92 & - \\
\hline
\end{tabular}

Spalling behaviour was analysed focusing on the Spalling Criterion $[29,30]$, given by Equation (3):

$$
\frac{\sigma 1-\sigma 3}{U C S}
$$

As a general guideline, spalling criterion value of 0.4 indicates damage initiation, beginning of fracturing; 0.7 indicates potential for rock burst to occur; values lower than 0.4 indicate no potential for burst of failure to develop.

\section{Results}

\subsection{Results from Geomatic Studies}

GNSS data were corrected by post-processing procedures using contemporary information recorded by five permanent stations (Borrasilano, La Spezia, Pisa, Borgo a Mozzano, and Ramiseto-Italy), allowing millimetric positional accuracy. The ellipsoidal heights were converted to orthometric heights in collaboration with the Italian Military Geographical Institute. The coordinates, collected in ETRF2000, were then converted to the Italian National Gauss Boaga system, and the absolute coordinates of all the targets, connected to the GNSS origin and TS reference direction, were obtained through a spatial $3 \mathrm{D}$ roto-translation.

Post-processing of M-TLS data was carried out through a registration/georeferencing technique in order to align the point clouds and to tie them one to each other within a single coordinate system (Table 5). The co-axial photos acquired during the survey were then processed and aligned to the point clouds (i.e., texture mapping; $[6,8]$ ) to produce a 3D photorealistic model suitable for photointerpretation.

Table 5. Information related to the M-TLS post-processing procedure.

\begin{tabular}{cccc}
\hline TLS & \# Scan Station & TRE & \# Points \\
\hline Macchietta 2014 & 9 & 0.004 & $70,225,499$ \\
\hline Macchietta-Fitta 2016 & 8 & 0.002 & $89,292,867$ \\
\hline Tacca Bianca 2016 & 14 & 0.003 & $88,003,157$ \\
\hline
\end{tabular}

TRE $=$ Target Registration Error (m).

\subsection{Change Detection Analysis Results}

The change detection analysis of the whole Macchietta quarry (step 1) allowed the understanding of morphological variations during the two years' time span of marble excavation. Figure 5 shows that $94.9 \%$ of distances $\left(\mathrm{L}_{\mathrm{M} 3 \mathrm{C} 2}\right)$ were smaller than the defined LOD $_{95 \%}$ (i.e., 1,355,462 non-significant changes; 73,095 significant changes), indicating general inactivity of the quarry walls. Surface significant changes due to excavation in the underground area ranged from -1.99 to $2.13 \mathrm{~m}$, with a mean value of $-0.066 \mathrm{~m}(\mu)$ and a standard deviation of $0.24 \mathrm{~m}$ ( $\sigma$-Figure 5 , Table 6 ). The maps of changes are coloured by grey points with zero value (non-significant changes) corresponding to $94.9 \%$, while blue 
points with a value equal to 1 (significant changes) represent a total of $5.1 \%$. These results were filtered in a range from -0.005 to $0.005 \mathrm{~m}$ (i.e., minimum detectable change) and represented by using a logarithmic colour scale, based on absolute distances (real numbers with the same absolute values and contrary sign, have the same colour in Figure 5).

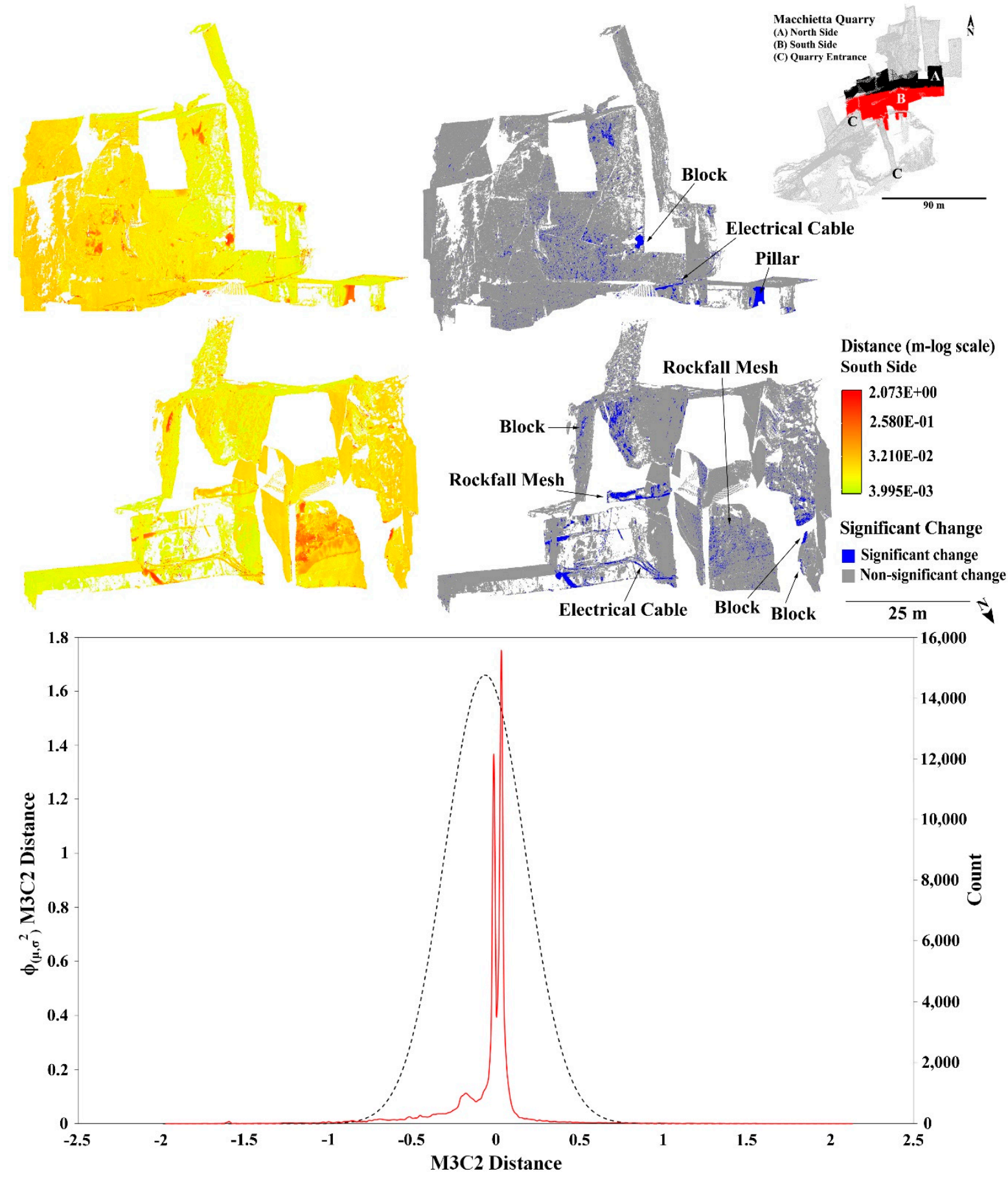

Figure 5. Maps of computed distance (left) and significant change (right) of the Northside of the quarry (A) and Southside of the quarry (B). The points of view are indicated by the north arrows. The scale bar is indicative only due to the perspective view. The inset map represents the top view of the Macchietta quarry with highlighted the North (A) and South (B) sectors. At the bottom $(C)$, the Gaussian distribution of the computed distances $\left(\phi_{(\mu, \sigma}{ }^{2}\right)$-dotted line $)$ corresponding to significant changes for the whole underground quarry. 
Table 6. Results from the change detection analysis.

\begin{tabular}{cccc}
\hline \multicolumn{4}{c}{ Significant Changes } \\
\hline Step & L $_{\text {M3C2 }}$ & $\mu$ & $\sigma$ \\
\hline$\# 1$ & {$[-1.990,2.130]$} & -0.066 & 0.240 \\
\hline$\# 2$ & {$[-0.668,0.163]$} & -0.070 & 0.120 \\
\hline
\end{tabular}

$\mathrm{L}_{\mathrm{M} 322}$ range of significant change due to excavation in the underground area $(\mathrm{m})$; significant change mean value $\mu(\mathrm{m})$; significant change standard deviation $\sigma(\mathrm{m})$.

As already discussed in Step 2, the identified unstable pillar underwent a high precision analysis that allowed us to highlight how structural deformations were massed through its eastern sidewall (Figure 6). The measured distance in significant changes $(65,832$ equal to $38.1 \%)$ ranged from -0.66 to $0.16 \mathrm{~m}$, with a mean value equal to $-0.07 \mathrm{~m}$ and a standard deviation of $0.12 \mathrm{~m}$ (Figure $6 \mathrm{c}$ and Table 6$)$. Non-significant changes $(107,252$ equal to $61.9 \%$ ) were detected through both the southern and the western sidewall of the pillar with a negligible displacement. As before for the whole Macchietta quarry, results were filtered in a range from -0.005 to $0.005 \mathrm{~m}$ and shown by using a linear scale.

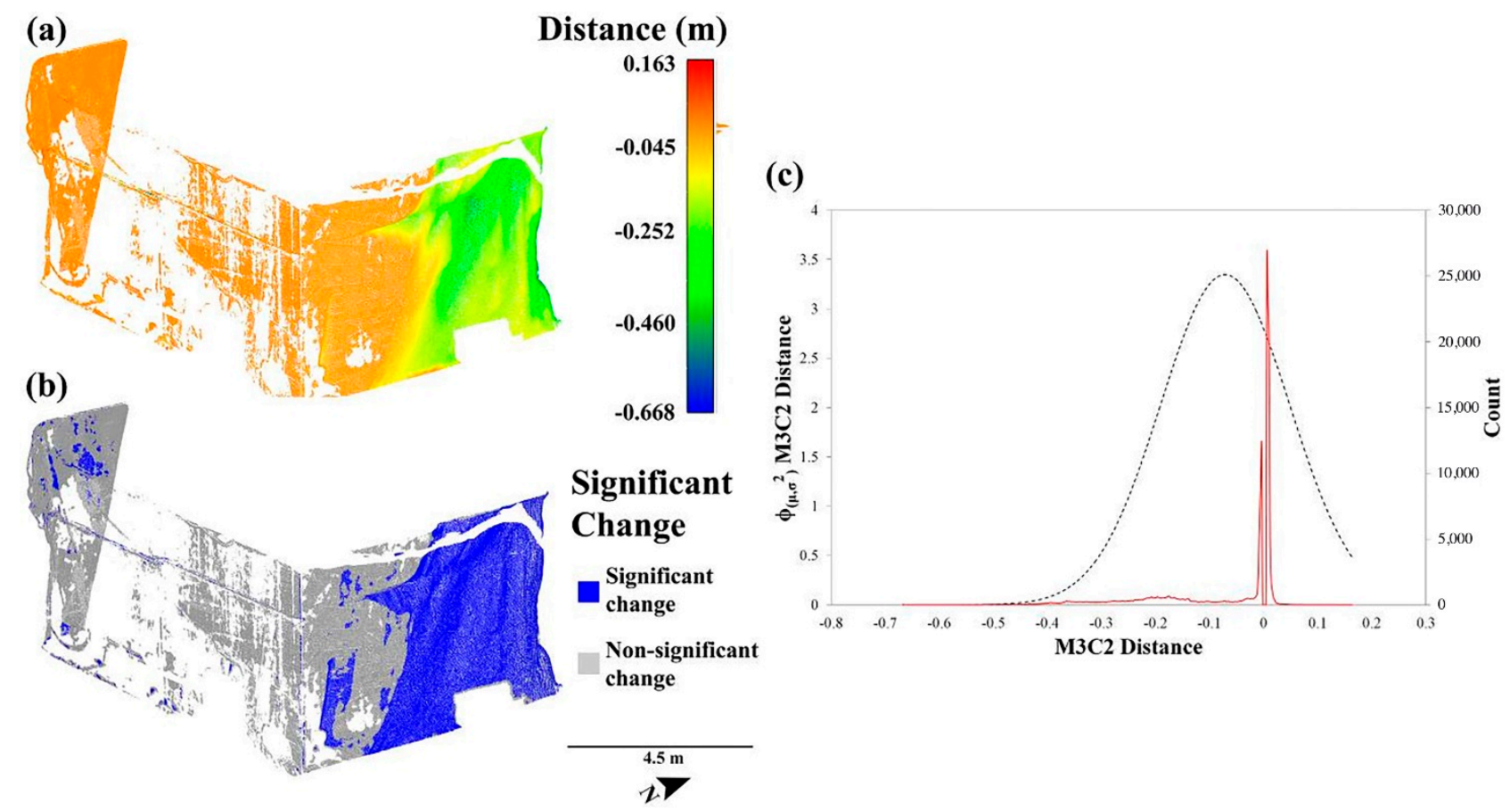

Figure 6. Maps of the computed distance (a) and significant change (b) in the analysed damaged pillar; the scale bar is indicative only due to perspective view. Gaussian distribution $\left(\phi_{\left(\mu, \sigma^{2}\right)}\right)$ of computed distances (m) corresponding to significant changes (c).

\subsection{Spalling Pillar Failure Analysis}

A simplified geometry and excavation sequence were used in the FEM model. The marble extraction locally changes the intensity and orientation of the principal stresses $(\sigma 1$ and $\sigma 3$ ), and these effects were very significant on the excavation sidewalls. As discussed by $\mathrm{Wu}$ and Pollard [31], these variations may result in the development of new fractures (i.e., spalling) that may form in a direction parallel to the induced $\sigma 1$ direction. Because of the elastic character of the model under analysis, the results would not include material yielding. Therefore, an elastic spalling criterion $[29,30]$ was used to quantify whether the induced stresses are sufficiently high (with respect to the assumed intact rock strength) to result in crack initiation and coalescence. Figure 7 (isotropic elastic material) and Figure 8 (transversely elastic anisotropic material) show the comparison between the induced 
stresses $(\sigma 1)$. Figures 7 and 8 also show the calculated spalling ratio, and it is assumed that spalling may occur when the ratio is greater than 0.4. Under those conditions, the numerical model shows that spalling of the pillar corners would be possible.

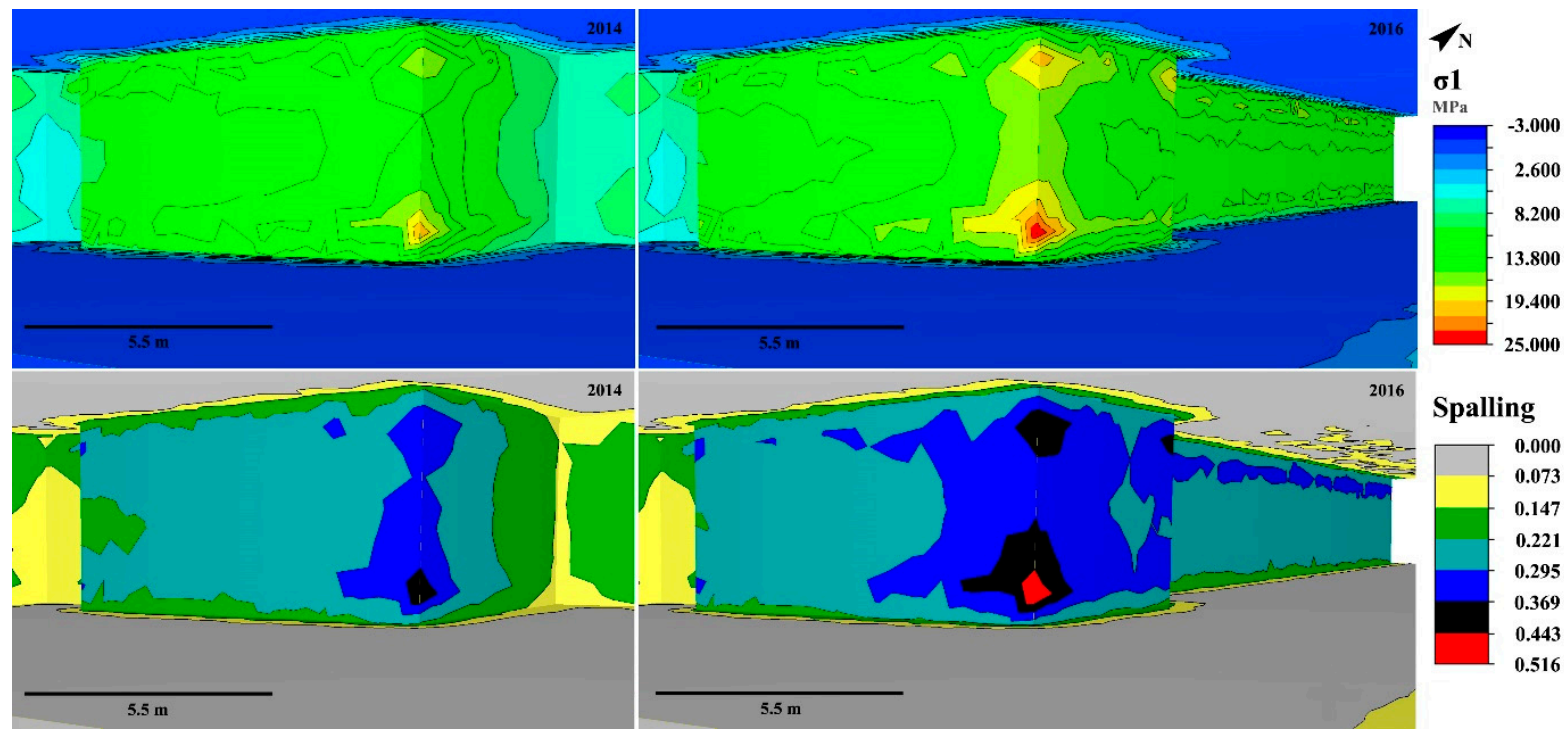

Figure 7. Comparison of major principal field stress $\sigma 1$ (top) and spalling ratio values (isotropic elastic material-bottom), as modelled for two scenarios representing two different stages in the Macchietta quarry excavation (year 2014 to the left, and year 2016 to the right). The scale bar is indicative only.

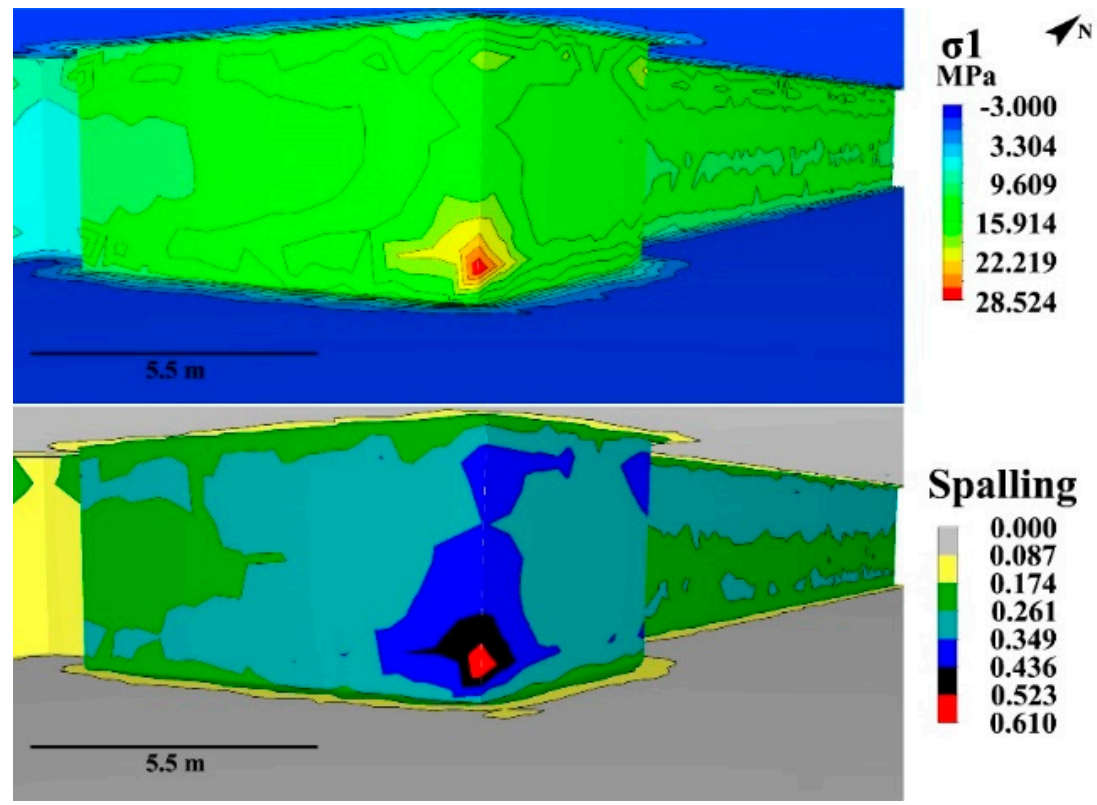

Figure 8. Spatial distribution of major principal field stress $\sigma 1$ (top) and spalling ratio values (bottom), considering transversely elastic anisotropic material (year 2016). The scale bar is indicative only.

Two different scenarios (including or not the excavation of the Fitta quarry above the pillar) clearly show how the observed damage may be related to the close proximity of this quarry, located only $6 \mathrm{~m}$ above and a few metres to the left with respect to the Macchietta quarry (Figure 9). 


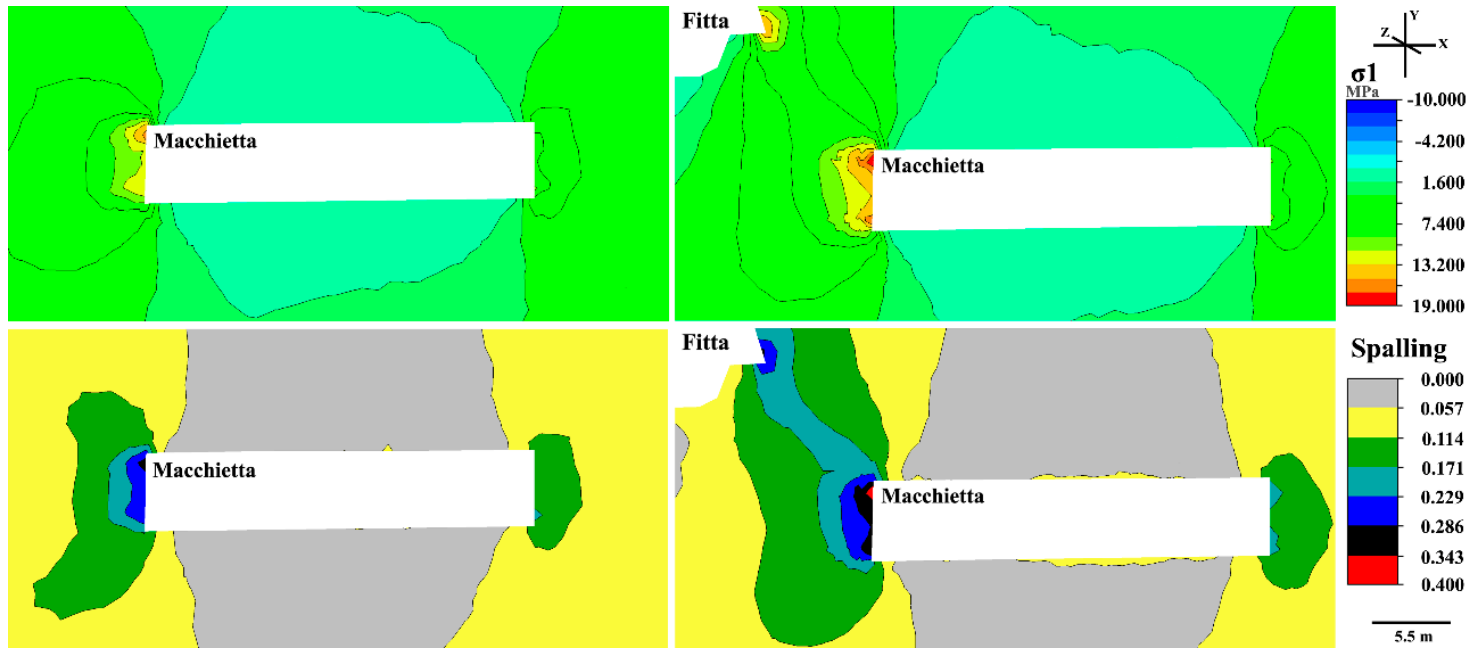

Figure 9. Zones of influence between contiguous openings (S-N look direction); major principal field stress (top) and spalling ratio values (bottom) considering isotropic elastic material and including the Fitta quarry (right) or not (left).

\section{Discussion}

The main goal of this research was to evaluate if M-TLS and subsequent 3D analysis (i.e., change detection) can be used to assess mining hazards in evolving environments, such as mining contexts, to minimize the risk for operators.

An aspect of fundamental importance for understanding the stress-strain behaviour of a rock mass at the advancing of excavation is the reconstruction of its geometrical setting. To acquire such data with high accuracy, the remote acquisition of spatial information related to the surfaces of the quarry was carried out by using the TLS technology.

TLS was used in order to carry out a point clouds comparison using the M3C2 algorithm. The possibility to acquire a huge amount of data in a very short time allowed to perform accurate 3D comparisons of M-TLS data. A key factor was represented by how the TLS surveys were aligned and integrated into the same coordinate system. This is an essential factor and a crucial step to perform a reliable change detection analysis. Indeed, it is important to reduce the systematic errors during the geomatic surveys avoiding further uncertainties during the point clouds comparison. This step was overcome by means of a topographic intersection using Iterative Closest Point algorithms [32] and many targets from the permanently installed network in unserved quarry areas. In this way, a systematic millimetric error equal to the final intersection calculation was added. Through this technique, it was possible to integrate the new topographic survey (year 2016) into the same coordinate system of the first one (year 2014). Thanks to carefully designed differences in reflectivity between the target centre and the main target surface, it was possible to achieve accurate and precise intersection results. Moreover, TS laser beam divergence was avoided by means of turning targets oriented perpendicular to the laser beam. This approach allows the use of a minimum number of intersection targets, in contrast with the alignment method that requires a greater and well-distributed number of targets (the accuracy increases with the number of reference points [33]).

The $\mathrm{M} 3 \mathrm{C} 2$ is a powerful, free and accurate algorithm that allows performing truthful change detection analysis using directly point cloud data. This approach allows avoiding useless approximations (e.g., comparisons among mesh models) and adds accuracy troubles (e.g., interpolation) during a change detection analysis [16]. The $\mathrm{M} 3 \mathrm{C} 2$ computes the local distance between two point clouds along the normal surface direction only if it intersects any point on the final point cloud. Moreover, in order to verify the distance measurement accuracy and the reliability of the occurred change, the algorithm estimates a confidence interval for each distance measurement. In this way, it is possible to obtain a robust computation of the source of uncertainty allowing to evaluate the impact of both local roughness and local density on the detected distance measurement. Nevertheless, 
some problems related to the morphological complexity of the quarry during distance computations have been faced. Indeed, a critical aspect is represented by normal computation during a change detection analysis. The surface normal vector is computed by fitting a plane to the neighbours defined by the normal scale " $\mathrm{D}$ " in the proximity of " $\mathrm{i}$ ". This method is robust to noise but very bad with sharp edges and corners [34]. Indeed, the reliability of the best-fit plane is related to the level of noise and the number/distance of neighbours [34]. Furthermore, a rough morphology can cause local shadowing in point clouds with related additional uncertainty in normal computation. To minimise the problems with the local surface model, it was chosen to divide the point clouds into 68 sub-parallel areas and run the change detection analysis by comparing every pair of point clouds separately. In this context, the change detection analysis was carried out by using different normal scale and projection scale values. This method allowed the avoiding of over- or under-estimation of distances $\left(\mathrm{L}_{\mathrm{M} 3 \mathrm{C} 2}\right)$ and consequently the presence of significant false changes, caused, for example, by missing data. Furthermore, it was possible to verify whether the normal scale was 20-25 times the roughness estimated at scale D for each point cloud pair and whether at least 4 points were used to compute the average position of each cloud (e.g., the eastern pillar wall is characterised by 470,32 and 216,80 points respectively for the 2016- and 2014-point clouds estimated by using a sphere with a radius of $0.25 \mathrm{~m}$ ).

In this context, the first approach was used to rapidly identify changed zones in the quarry; the second one, instead, represents an in-depth analysis of the rate of morphological variations (from decimetre to millimetre) that occurred to an internal pillar during the quarrying activities. This high-precision analysis allowed to keep details because of smallscale values. Indeed, Lague et al. [16] proved that using large normal and projection scale values can smooth out the details causing approximations during the distance computation. The analysis highlights how structural deformations are characterised by a general negative rate (i.e., spalling) with a post-failure area concentrated through the eastern wall of the pillar. The other walls can be classified as truly stable surfaces, probably due to the presence of supports.

The change detection analysis through the whole quarry showed up general stability of the rock surfaces. However, considering that the $\mathrm{LOD}_{95 \%}$ test is a function of point density and local cloud roughness, the non-changed computed value $(94.9 \%)$ can be characterised by an overrated interpretation. Indeed, areas with low point density (e.g., upper parts of the quarry) or local high values of roughness (e.g., objects not completely removed in the first step) can influence the statistical analysis. Changing areas, instead, correspond to unstable or potentially unstable blocks and rock debris, naturally fallen or removed during maintenance work, meshes for rockfall protection, electrical cables and water tubes not eliminated during the point cloud editing.

To improve the reliability and reduce uncertainties during the change detection analysis, further approaches may be carried out by using as much as possible the same scan positions from different temporal surveys. This can allow avoiding shadows and missing point data that can affect the local roughness and the local density of clouds determining a better evaluation of the change rate during the statistical analysis. Furthermore, in accordance with Lague et al. [16], the use of non-changing fixed reference objects in the different temporal scans can be a useful method to check the result's reliability during the M3C2 analysis.

FEM numerical analysis was successfully used in providing a better understanding of the mechanisms that likely controlled the rock mass damage observed in the pillar of the Macchietta quarry. Despite its simplified modelling, there is good conformity between the change detection results and the field observations (e.g., location of spalling damage). The FEM analysis demonstrates that even though the stresses do not reach very high magnitudes, they may be large enough to induce spalling in the direction of the maximum principal stress near the excavated boundaries. Indeed, the spalling ratio in some areas of the pillar reaches values greater than 0.4 , which would indicate damage initiation and fracturing $[29,30]$. Therefore, the numerical modelling successfully indicated stress 
redistribution in consequence of underground excavation capable of causing spalling failure in the area of the pillar under examination. Even though any kind of discontinuity is considered in the FEM analysis, this is an important result that allows for a better understanding of the failure mechanism on the Macchietta quarry and can help in adopting proper prevention measures. The modelling results have also shown the role of proximity of the two underground quarries and the effects in terms of stress redistribution induced by the presence of the Fitta quarry few meters above. Indeed, the average state of stress in the zone of influence of the structure is of primary importance on the post-excavation stress distribution in the excavation near-field rock [35].

However, the continuum nature of the FEM analysis is such that it was not possible to explicitly account for the presence of foliation and other structural planes of weakness. Field geological observations and the interpretation of TLS data suggest that the S1 foliation may play a significant role in the observed pillar damage by locally redistributing stresses. Future research should focus on this aspect in order to obtain a complete quantitative and qualitative assessment of the geomechanical mining risk.

To conclude, TLS, point clouds comparison and numerical modelling allowed the obtaining of a rock mechanic-based knowledge related to the risk-design assessment with the aim of providing the knowledge to prevent re-occurrence in the quarry planning, underlying failure mechanism of the identified pillar failure.

\section{Conclusions}

Different approaches, such as change detection analysis and numerical modelling, have been presented to study the stability that has impacted the surfaces of an underground marble quarry in the Apuan Alps (Italy). The proposed approaches fully took account of modern methodologies in order to study morphometric and structural changes of the underground excavation. Furthermore, a geo-structural analysis was carried out through modern and classical methods in order to obtain the complete knowledge necessary to understand and guide the rock mass behaviour for stability numerical modelling.

The morphometric changes within the quarry were analysed by using the $\mathrm{M} 3 \mathrm{C} 2$ CloudCompare freeware algorithm. This study highlights how a change detection analysis is suitable to control morphological variations in a complex environment and to obtain a full knowledge of the rock mass behaviour during the time, to maintain safety, to ensure adequate quality control of the quarrying operations, and to plan future developments of the extraction. In particular, a high-definition change detection analysis represents a suitable method for controlling mining and industrial processes as well as for identifying the root cause of a failure and managing complex stability analysis using advanced numerical tools. To examine the $\mathrm{M} 3 \mathrm{C} 2$ distance results, a proper FEM numerical approach was used. Results demonstrate that a preliminary numerical approach allows focusing the attention on the stress redistribution around complex underground excavations and limit the impact that a complex geological history would have on the interpretation of results.

Following the results from the FEM analysis, a further Finite-Discrete Element Method numerical approach should be used to analyse the transition from continuous to discontinuous state in the pillar, including the presence of discontinuities. In this context, a hybrid analysis could be carried out to study how stress redistribution leads to the propagation and coalescence of the pre-existing fractures and the formation of new cracks.

Author Contributions: Data curation, Claudio Vanneschi and Giovanni Mastrorocco; methodology, Giovanni Mastrorocco; project administration, Riccardo Salvini; supervision, Riccardo Salvini; validation, Riccardo Salvini; writing — original draft, Riccardo Salvini, Claudio Vanneschi and Giovanni Mastrorocco; writing-review and editing, Riccardo Salvini. All authors have read and agreed to the published version of the manuscript.

Funding: This research received no external funding.

Institutional Review Board Statement: Not applicable.

Informed Consent Statement: Not applicable. 


\section{Data Availability Statement: Not applicable.}

Acknowledgments: The authors gratefully acknowledge the assistance of the personal of the Macchietta quarry and particularly the geologist Landucci N. The authors also wish to thank Massa G. and Pieruccioni D. for their support of the geological survey. A special thank goes to Elmo D. for his help in numerical modelling.

Conflicts of Interest: The authors declare no conflict of interest.

\section{References}

1. Lato, M.; Diederichs, M.S.; Hutchinson, D.J.; Harrap, R. Optimization of LiDAR scanning and processing for automated structural evaluation of discontinuities in rockmasses. Int. J. Rock Mech. Min. Sci. 2009, 46, 194-199. [CrossRef]

2. Assali, P.; Grussenmeyer, P.; Villemin, T.; Pollet, N.; Viguier, F. Surveying and modeling of rock discontinuities by terrestrial laser scanning and photogrammetry: Semi-automatic approaches for linear outcrop inspection. J. Struct. Geol. 2014, 66, 102-114. [CrossRef]

3. Deliormanli, A.H.; Maerz, N.H.; Otoo, J. Using terrestrial 3D laser scanning and optical methods to determine orientations of discontinuities at a granite quarry. Int. J. Rock Mech. Min. Sci. 2014, 66, 41-48. [CrossRef]

4. Salvini, R.; Mastrorocco, G.; Esposito, G.; Di Bartolo, S.; Coggan, J.; Vanneschi, C. Use of a remotely piloted aircraft system for hazard assessment in a rocky mining area (Lucca, Italy). Nat. Hazards Earth Syst. Sci. 2018, 18, 287-302. [CrossRef]

5. Francioni, M.; Salvini, R.; Stead, D.; Litrico, S. A case study integrating remote sensing and distinct element analysis to quarry slope stability assessment in the Monte Altissimo area, Italy. Eng. Geol. 2014, 183, 290-302. [CrossRef]

6. Vanneschi, C.; Salvini, R.; Massa, G.; Riccucci, S.; Borsani, A. Geological 3D modeling for excavation activity in an underground marble quarry in the Apuan Alps (Italy). Comput. Geosci. 2014, 69, 41-54. [CrossRef]

7. Riquelme, A.; Cano, M.; Tomás, R.; Abellán, A. Identification of Rock Slope Discontinuity Sets from Laser Scanner and Photogrammetric Point Clouds: A Comparative Analysis. Procedia Eng. 2017, 191, 838-845. [CrossRef]

8. Mastrorocco, G.; Salvini, R.; Vanneschi, C. Fracture mapping in challenging environment: A 3D virtual reality approach combining terrestrial LiDAR and high definition images. Bull. Eng. Geol. Environ. 2018, 77, 691-707. [CrossRef]

9. Kromer, R.A.; Hutchinson, D.J.; Lato, M.J.; Gauthier, D.; Edwards, T. Identifying rock slope failure precursors using LiDAR for transportation corridor hazard management. Eng. Geol. 2015, 195, 93-103. [CrossRef]

10. Salvini, R.; Vanneschi, C.; Coggan, J.S.; Mastrorocco, G. Evaluation of the Use of UAV Photogrammetry for Rock Discontinuity Roughness Characterization. Rock Mech. Rock Eng. 2020, 53, 3699-3720. [CrossRef]

11. Firpo, G.; Salvini, R.; Francioni, M.; Ranjith, P.G. Use of Digital Terrestrial Photogrammetry in rocky slope stability analysis by Distinct Elements Numerical Methods. Int. J. Rock Mech. Min. Sci. 2011, 48, 1045-1054. [CrossRef]

12. Francioni, M.; Salvini, R.; Stead, D.; Giovannini, R.; Riccucci, S.; Vanneschi, C.; Gulli, D. An integrated remote sensing-GIS approach for the analysis of an open pit in the Carrara marble district, Italy: Slope stability assessment through kinematic and numerical methods. Comput. Geotech. 2015, 67, 46-63. [CrossRef]

13. Salvini, R.; Mastrorocco, G.; Seddaiu, M.; Rossi, D.; Vanneschi, C. The use of an unmanned aerial vehicle for fracture mapping within a marble quarry (Carrara, Italy): Photogrammetry and discrete fracture network modeling. Geomat. Nat. Hazards Risk 2017, 8, 34-52. [CrossRef]

14. Wiatr, T.; Reicherter, K.; Papanikolaou, I.; Fernández-Steeger, T.; Mason, J. Slip vector analysis with high resolution t-LiDAR scanning. Tectonophysics 2013, 608, 947-957. [CrossRef]

15. Han, J.Y.; Guo, J.; Jiang, Y.S. Monitoring tunnel deformations by means of multi-epoch dispersed 3D LiDAR point clouds: An improved approach. Tunn. Undergr. Space Technol. 2013, 38, 385-389. [CrossRef]

16. Lague, D.; Brodu, N.; Leroux, J. Accurate 3D comparison of complex topography with terrestrial laser scanner: Application to the Rangitikei canyon (N-Z). ISPRS J. Photogramm. Remote Sens. 2013, 82, 10-26. [CrossRef]

17. Goodwin, N.R.; Armston, J.; Stiller, I.; Muir, J. Assessing the repeatability of terrestrial laser scanning for monitoring gully topography: A case study from Aratula, Queensland, Australia. Geomorphology 2016, 262, 24-36. [CrossRef]

18. Esposito, G.; Mastrorocco, G.; Salvini, R.; Oliveti, M.; Starita, P. Application of UAV photogrammetry for the multi-temporal estimation of surface extent and volumetric excavation in the Sa Pigada Bianca open-pit mine, Sardinia, Italy. Environ. Earth Sci. 2017, 76, 103. [CrossRef]

19. Elmo, D.; Clayton, C.; Rogers, S.; Beddoes, R.; Greer, S. Numerical simulations of potential rock bridge failure within a naturally fractured rock mass. In Proceedings of the International Symposium on Slope Stability in Open Pit Mining and Civil Engineering, Vancouver, BC, Canada, 18-21 September 2011; Eberhardt, E.S.D., Ed.;

20. Coggan, J.; Gao, F.; Stead, D.; Elmo, D. Numerical modelling of the effects of weak immediate roof lithology on coal mine roadway stability. Int. J. Coal Geol. 2012, 90, 100-109. [CrossRef]

21. Gao, F.; Stead, D.; Coggan, J. Evaluation of coal longwall caving characteristics using an innovative UDEC Trigon approach. Comput. Geotech. 2014, 55, 448-460. [CrossRef]

22. Carmignani, L.; Kligfield, R. Crustal extension in the northern Apennines: The transition from compression to extension in the Alpi Apuane Core Complex. Tectonics 1990, 9, 1275-1303. [CrossRef] 
23. Meccheri, M.; Bellagotti, E.; Berretti, G.; Conti, P.; Dumas, F.; Mancini, S.; Molli, G. The Mt. Altissimo marbles (Apuane Alps, Tuscany): Commercial types and structural setting. Boll. Della Soc. Geol. Ital. Ital. J. Geosci. 2007, 126, 25-35.

24. Giglia, G. Geologia dell'alta Versilia settentrionale (tav. Monte Altissimo). In Memorie Della Società Geologica Italiana; Società Geologica Italiana: Rome, Italy, 1967; Volume 6, pp. 67-95.

25. Conti, P.A.; Carmignani, L.; Giglia, G.; Meccheri, M.; Fantozzi, P.L. Evolution of geological interpretations in the Alpi Apuane Metamorphic Complex, and their relevance for the geology of the Northern Apennines. In The "Regione Toscana" Project of Geological Mapping; Geological Survey of Tuscany Region: Florence, Italy, 2004; pp. 241-262.

26. Brasington, J.; Langham, J.; Rumsby, B. Methodological sensitivity of morphometric estimates of coarse fluvial sediment transport. Geomorphology 2003, 53, 299-316. [CrossRef]

27. Hoek, E.; Brown, T. Underground Excavations in Rock; CRC Press: Boca Raton, FL, USA, 1980; ISBN 0900488-54-9.

28. Elmo, D.; Moffitt, K.; Carvalho, J. Synthetic rock mass modelling: Experience gained and lessons learned. In Proceedings of the 50th US Rock Mechanics/Geomechanics Symposium, Houston, TX, USA, 26-29 June 2016; Volume 3.

29. Castro, L.A.M.; McCreath, D.R.; Kaiser, P.K. Rockmass strength determination from breakouts in tunnels and boreholes. In Proceedings of the 8th ISRM Congress, Tokyo, Japan, 25-29 September 1995.

30. Castro, L.A.M.; Grabinski, M.W.; McCreath, D.R. Damage initiation through extension fracturing in a moderately jointed brittle rock mass. Int. J. Rock Mech. Min. Sci. Geomech. Abstr. 1997, 34, 110. [CrossRef]

31. Wu, H.; Pollard, D. An experimental study of the relationship between joint spacing and layer thickness. J. Struct. Geol. 1995, 17, 887-905. [CrossRef]

32. Besl, P.J.; McKay, N.D. A Method for Registration of 3-D Shapes. IEEE Trans. Pattern Anal. Mach. Intell. 1992, 14, 239-356. [CrossRef]

33. McAnuff, C. Stress Inversion Using LiDAR Tunnel Deformation Measurements; Queen's University: Kingston, ON, Canada, 2016.

34. CloudCompare CloudCompare wiki. Available online: https://www.cloudcompare.org/doc/wiki/index.php?title=Main_Page (accessed on 19 July 2021).

35. Brady, B.H.G.; Brown, E.T. Rock Mechanics for Underground Mining, 3rd ed.; Kluwer Academic Publishers: Amsterdam, The Netherlands, 2006. 